\title{
ГАЗОВАЯ ХРОМАТО-МАСС-СПЕКТРОМЕТРИЯ СТЕРОИДОВ МОЧИ - ИННОВАЦИОННЫЙ МЕТОД В ЛАБОРАТОРНОЙ ДИАГНОСТИКЕ ЗАБОЛЕВАНИЙ НАДПОЧЕЧНИКОВ
}

\author{
Шафигуллина 3.Р., Ворохобина Н.В., Великанова Л.И., Малеваная Е.В., Стрельникова Е.Г., Калугина В.В. \\ Северо-Западный государственный медицинский университет им. И.И. Мечникова Минздрава России, \\ Санкт-Петербург
}

ЦЕЛЬ: установить биохимические признаки заболеваний гипофизарно-надпочечниковой системы путем исследования стероидных профилей мочи (СПМ) методом газовой хромато-масс-спектрометрии (ГХМС) для улучшения диагностики и тактики ведения пациентов.

МАТЕРИАЛЫ И МЕТОДЫ: обследовано 40 больных синдромом Кушинга надпочечникового генеза (СКН), 42 больных синдромом Кушинга гипофизарного генеза (СКГ), 49 больных адренокортикальным раком (АКР). Методом газовой хромато-масс-спектрометрии (ГХМС) исследовали стероидные профили мочи (СПМ) на газовом хромато-масс-спектрометре SHIMADZU GCMS - QP2010 ULTRA (идентифицировано 70 стероидов). Статистическая обработка данных проводилась с использованием программного пакета STATISTICA for WINDOWS (версия 10).

PЕЗУЛЬТАТЫ: У больных СКН установлено увеличение экскреции с мочой (ЭМ) кортизола (F), кортизона (Е), 5ß-тетрагидрометаболитов кортизола (THF), кортикостерона (ТНВ), кортизона (ТНЕ) и 11-дезоксикортизола (THS), дигидрокортизола, дигидрокортизона и кортолов, а также уменьшение ЭМ дегидроэпиандростерона (DHEA) и метаболитов DHEA и андростендиона. У больных СКГ в сравнении с показателями больных СKH обнаружено увеличение ЭМ андростерона (An), этиохоланолона (Et), DHEA и его метаболитов, соотношения (5a-THF+5 $\beta-\mathrm{THF}+\mathrm{THE}) / \mathrm{THS}$ (>36). По данным многофакторного анализа для дифференциальной диагностики данных заболеваний наиболее информативными $(\mathrm{p}<0,0001)$ являются значения $\mathrm{Et}$, An, 16-охо-андростендиола (16-охо-dA2), андростентриола (dA3), THS, суммы а- и $\beta$ - кортолов, прегнантриола (Р3), прегнандиола (P2), прегнендиола (dP2) и 16-OH-dP2.

Получено 18 основных биомаркеров AKP: THS, DHEA и его метаболиты (dA2-17ß, 16-OH-DHEA, 16-охо-dA2, dA3), Et, P2, P3, dP2, прегнентриол-3a (dP3-3a), 16-ОН-dP2-3а и неклассические 5-еnе-прегнены. Увеличение ЭМ данных показателей свидетельствует о наличии АКР (чувствительность и специфичность более 95\%). Получены 3 варианта СПМ у больных АКР: повышение ЭМ андрогенов и THS (71\% обследованных), повышение ЭМ THS при нормальной экскреции андрогенов (16\%), повышение андрогенов при нормальной экскреции THS (13\%). Увеличение ЭМ P2, Р3 и 5-еnе-прегненов получены у больных АКР при всех 3-х вариантах СПМ.

ВЫВодЫ: разработка новых диагностических критериев в результате изучения метаболомики стероидов методом газовой хромато-масс-спектрометрии позволяет оптимизировать дифференциальную диагностику синдрома Кушинга надпочечникового и гипофизарного генеза и улучшить диагностику адренокортикального рака на ранних стадиях.

КЛЮЧЕВЫЕ СЛОВА: газовая хромато-масс-спектрометрия, синдром Кушинга адренокортикальный рак. 